\title{
Molecular characterization of the gene pool of Exorista sorbillans (Diptera: Tachinidae) a parasitoid of silkworm, Bombyx mori, in India
}

\author{
Shankar N. CHATTERJEE*, Thampiyath P. MOHANDAS and TAnUshree TARAPHDAR \\ Molecular Genetics, SeriBiotech Laboratory, Central Silk Board, Campus-Kodathi; Sarjapur Road, P.O: Carmelram, \\ Bangalore-560035, Karnataka, India
}

Key words. Population genetic structure, microevolution, Exorista sorbillans, endoparasitoid, Bombyx mori, molecular fingerprints, molecular ecology

\begin{abstract}
Exorista sorbillans, the uzi fly, is a serious tachinid pest of silkworm and is present in all silk producing areas of Asia. Assuming that E.sorbillans was accidentally transported from West Bengal to southern states of India, its population genetic structure was studied using 13 ISSR, 3 RAPD, two sets of universal primers and two sets of primers designed from a lepidopteran repeat sequence. Statistical analyses of DNA markers revealed significant genetic variability between the E. sorbillans populations from 4 different geographic locations (within $400 \mathrm{~km}$ of one another) in the southern states and the one from West Bengal (Murshidabad). Multivariate and discriminant function analyses indicate that the $E$. sorbillans from south India has diverged from the original gene pool of West Bengal and is suitable for studying the microevolution of adaptation to the conditions prevailing in the different cocoon producing areas in India.

Abbreviations used. GP = geographic population; ISSR = Inter Simple Sequence Repeat; PCR = Polymerase Chain Reaction; RAPD = Random Amplified Polymorphic DNA; SPSS = Statistical Package for Social Sciences; UBC = University of British Columbia; UNIV = Universal.
\end{abstract}

\section{INTRODUCTION}

Exorista sp., is well known as uzi flies in those areas of the world where sericulture is practicised. These flies are tachinid endoparasitoids of all kinds of silkworm and other lepidopteran species (Vander Wulp, 1896; Ghosh, 1949). The species parasitizing the monophagous silkworm, Bombyx mori L., in India, is Exorista sorbillans, syn. Tricholyga bombycis or E. bombycis (Tachinidae: Exoristini) (Cotes, 1889). This parasitoid is common in southern China, India, Bangladesh, Japan, South Korea, Thailand and Vietnam (Ghosh, 1949; Sengupta et al., 1990).

In West Bengal, E. sorbillans is present in all sericulture areas (Mukherjee, 1899) except above $400 \mathrm{~m}$ in the hilly regions. The endoparasitoid arrived in south India and became a pest of silkworm there in 1980 (Samson, 1980). This is attributed to its transportation in live cocoons from West Bengal to Hosakote, a town near Bangalore. It is thought that it then gradually spread to nearby sericulture areas in Karnataka, Andhra Pradesh and Tamilnadu (Samson, 1980; Narayanaswamy \& Devaiah, 1998).

This is the first report on the population genetic structure of Exorista sorbillans (five geographic populations or GPs) from four locations within an area with a perimeter of $1600 \mathrm{~km}$ around Bangalore, Karnataka and one from Murshidabad, one of the most traditional silk producing areas of West Bengal.

\section{MATERIALS AND METHODS}

Uzi fly populations. Exorista maggots or live pupae were collected from a rearing house of SeriBiotech Laboratory at Kodathi (GP 5), cocoon markets at Channapatna (GP 3), Ramanagaram (GP 4), all the three from Karnataka, one from Dharmavaram (GP 2), near Anantapur of Andhra Pradesh and another from the stock maintained at the Central Sericulture Research \& Training Institute, Murshidabad, West Bengal (GP 1). The two cocoon markets at Channapatna and Ramanagaram in Bangalore are only $10 \mathrm{~km}$ apart and cater for the needs of sericulture farmers of the area, near and far. GP refers to a geographical population of $E$. sorbillans collected from a specific area. The silk farm at Kodathi is an isolated place and has a perimeter of $10 \mathrm{~km}$, supports a few cocoon growers and thus the population can be considered as a natural population with very little chance of out-crossing, the flight range of E. sorbillans being less than $3 \mathrm{~km}$ (Narayanaswamy et al., 1994).

DNA extractions. DNA was extracted both from individual maggots / pupae or en masse from a minimum of five maggots / pupae, by either phenol-chloroform extraction or by using a genomic DNeasy kit (QIAGEN, Hilden, Germany). The DNA extracted en-masse and individually will be referred to as $\mathrm{DNA}^{\text {mass }}$ and DNA ${ }^{\text {ind }}$, respectively. Extracted DNA was subjected to further purification and dilution as described by Sethuraman et al. (2002). Quantification was done using electrophoresis on $0.8 \%$ agarose (GibcoBRL, Life Technologies, Paisley, Scotland, UK) gel and the result compared with uncut lambda DNA ( New England Biolabs Inc, Beverley, MA, USA).

Primers. Four groups of primers were used: (1) twelve dinucleotide and one trinucleotide ISSR primer of UBC Kit 9 (coded numerically), selected on the basis of earlier experiments, (2) three UBC RAPD primers (OPH 5, OPI 13 and 15) selected by random testing, (3) two universal primers, and (4) two pairs of primers, SBL534R and SBL578R, designed by the senior author on the basis of specific repeat sequences of Bombyx mori. PCR was done with a minimum of three $\mathrm{DNA}^{\text {ind }}$ and one DNA ${ }^{\text {mass }}$, from each GP.

PCR, separation of amplified products and scoring. PCR was done with a MJ Research Thermocycler PTC 200 in 25 or $30 \mu \mathrm{l}$ of reaction mixture having a $\mathrm{MgCl}_{2}$ concentration of 2.5 $\mathrm{mM}$ for ISSR, $2.0 \mathrm{mM}$ for RAPD, and 0.3 unit of Taq DNA polymerase per reaction. For other primers, the concentration of

* Corresponding author. B14/156 Kalyani, Nadia 741235, West Bengal, INDIA; e-mail: shankerc09@yahoo.com 


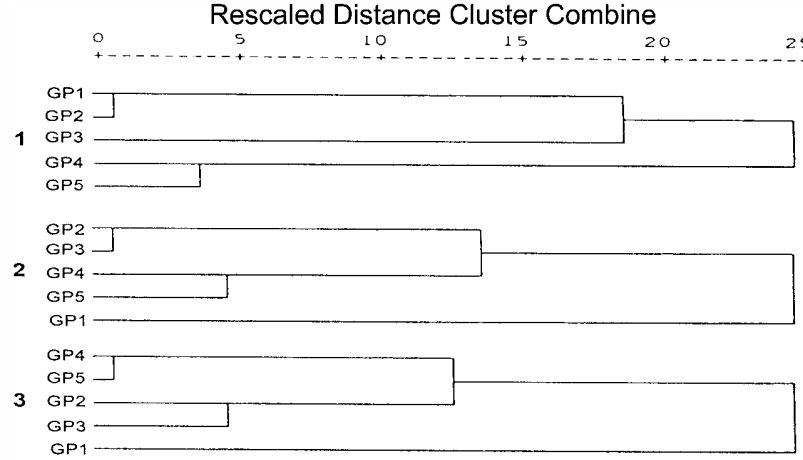

Fig. 1. Three dendrograms based on cluster analysis of the DNA profiles of five DNA ${ }^{\text {mass }}$ from five geographic populations (GP 1 - GP 5) using Anderberg's (1), Jaccard's (2) and squared Euclidean $D^{2}$ statistics (3).

$\mathrm{MgCl}_{2}$ was suitably adjusted to get the best amplification. Taq polymerases came from Bangalore Genei (Bangalore, India), Genetaq (Singapore), and MBI (Fermentas, USA). However, for a particular type of primer, the $T a q$ polymerase from only one source was used.

The thermal cycles adopted for amplification were different for the three groups of primers. These were: (a) preheating at $94^{\circ} \mathrm{C}$ for $2 \mathrm{~min}$ followed by 35 cycles of $94^{\circ} \mathrm{C}$ for $0.5 \mathrm{~min}, 50^{\circ} \mathrm{C}$ for $0.5 \mathrm{~min}, 72^{\circ} \mathrm{C}$ for $2 \mathrm{~min}$ and final extension at $72^{\circ} \mathrm{C}$ for 10 min for ISSR primers; (b) preheating at $93^{\circ} \mathrm{C}$ for $2 \mathrm{~min}$ followed by 45 cycles of $93^{\circ} \mathrm{C}$ for $1 \mathrm{~min}, 36^{\circ} \mathrm{C}$ for $1 \mathrm{~min}, 72^{\circ} \mathrm{C}$ for $2 \mathrm{~min}$ and final extension at $72^{\circ} \mathrm{C}$ for $10 \mathrm{~min}$ for UBC RAPD primers; (c) preheating for $4 \mathrm{~min}$ at $94^{\circ} \mathrm{C}$ and 36 cycles of $94^{\circ} \mathrm{C}$ for 1 min, $46^{\circ} \mathrm{C}$ for $1 \mathrm{~min}, 72^{\circ} \mathrm{C}$ for $2 \mathrm{~min}$ followed by a final extension for $15 \mathrm{~min}$ at $72^{\circ} \mathrm{C}$ for UNIV1 primers; (d) preheating for 4 min at $94^{\circ} \mathrm{C}$ followed by 36 cycles of $94^{\circ} \mathrm{C}$ for $1 \mathrm{~min}, 55.4^{\circ} \mathrm{C}$ for $1 \mathrm{~min}, 72^{\circ} \mathrm{C}$ for $2 \mathrm{~min}$ and finally extension at $72^{\circ} \mathrm{C}$ for 15 min for UNIV2 primers, and (e) preheating for 4 min at $94^{\circ} \mathrm{C}$ followed by 36 cycles of $94^{\circ} \mathrm{C}$ for $1 \mathrm{~min}, 54^{\circ} \mathrm{C}$ for $1.5 \mathrm{~min}, 72^{\circ} \mathrm{C}$ for $1 \mathrm{~min}$ with final extension at $72^{\circ} \mathrm{C}$ for $10 \mathrm{~min}$ for SBL534R and SBL578R primers.

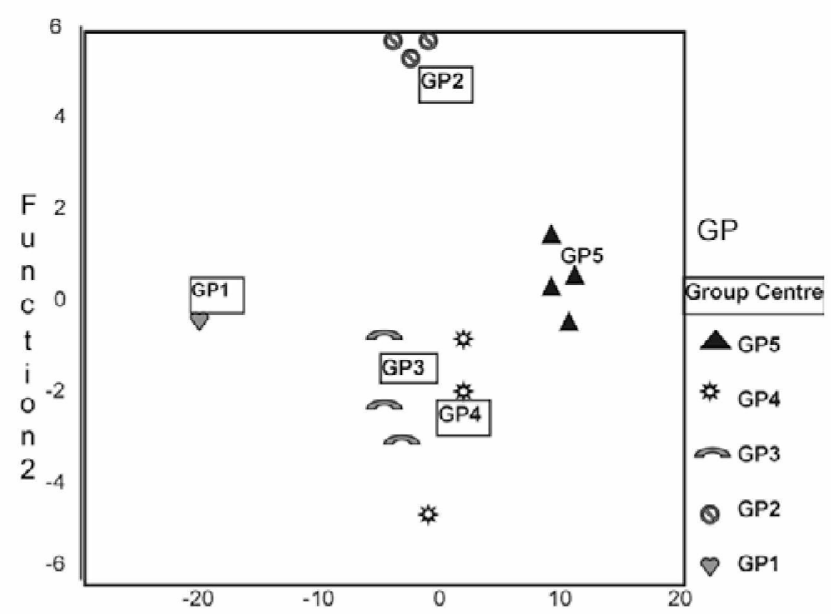

Function 1

Fig. 2. Plotting of the five GPs (marked 1-5) in a matrix based on a discriminant function analysis. The rectangles with the GP numbers denote the estimated centres for the five GPs. The variability of the respective GPs is indicated by different symbols.
TABLE 1. Results of the "Tests of Between-Subjects Effects" for the profiles generated with 13 ISSR and 3 RAPD primers using mass genomic DNA of E. sorbillans from the five GPs detailed in the text. Only the markers showing significant contributions to variability are shown. ${ }^{*}$, values in parentheses denote degrees of freedom.

\begin{tabular}{|c|c|c|c|}
\hline $\begin{array}{l}\text { Dependent } \\
\text { variable }\end{array}$ & Mean square & F-value & P-value \\
\hline \multicolumn{4}{|c|}{${ }^{*}$ Corrected model (5) } \\
\hline B810.01 & 0.23 & 3.7 & 0.037 \\
\hline B810.05 & 0.59 & 5.93 & 0.008 \\
\hline B810.06 & 0.23 & 3.7 & 0.037 \\
\hline B810.08 & 0.22 & 3.25 & 0.053 \\
\hline B810.09 & 0.22 & 3.25 & 0.053 \\
\hline B810.15 & 0.23 & 3.7 & 0.037 \\
\hline B810.17 & 0.37 & 5.94 & 0.008 \\
\hline B811.05 & 0.48 & 8.18 & 0.003 \\
\hline B811.13 & 0.51 & 5.59 & 0.01 \\
\hline B812.08 & 0.64 & 8.84 & 0.002 \\
\hline B855.08 & 0.47 & 4.32 & 0.024 \\
\hline B881.05 & 0.34 & 4.71 & 0.018 \\
\hline B881.09 & 0.52 & 3.7 & 0.037 \\
\hline B881.12 & 0.47 & 3.34 & 0.049 \\
\hline \multicolumn{4}{|c|}{ GPs (4) } \\
\hline B811.13 & 0.48 & 5.25 & 0.015 \\
\hline B812.08 & 0.74 & 10.25 & 0.001 \\
\hline B855.08 & 0.57 & 5.29 & 0.015 \\
\hline B881.09 & 0.64 & 4.55 & 0.024 \\
\hline B881.12 & 0.53 & 3.8 & 0.04 \\
\hline
\end{tabular}

PCR products were separated on a $1.5 \%$ agarose gel using Tris-Boric-EDTA (ethylene diamine tetraacetic acid) buffer, stained with ethidium bromide and photographed with a Nikon FM2 SLR (Sethuraman et al., 2002).

Statistical analysis. Binary scoring was transferred to SPSS format (SPSS/PC+ 10.0 version; M.J. Norusis, SPSS Inc., Chicago) for all the analyses. The molecular profiling was subjected to an analysis of genetic variability by multivariate analysis, hierarchical clustering (on the basis of five different statistics and an algorithm of average linkage between groups) and analysis of discriminant functions (DFA) based on Mahalanobis Distances $\left(D^{2}\right)$ statistics (www.spss.com).

\section{RESULTS}

A total of 138 markers, ranging between $0.3 \mathrm{~kb}$ to $3.0 \mathrm{~kb}$, were scored from ISSR profiles of which $61.4 \%$ were polymorphic. Three RAPD primers generated an average of 10.6 markers/primer, but with a significantly $(\mathrm{t}=2.31 ; \mathrm{P}=0.016)$ lower level of polymorphism $(43.7 \%)$.

The multivariate analysis of "between subject effects" of the five DNA ${ }^{\text {mass }}$ samples ascertained the significance of the contribution of selected independent variables (DNA markers in this case). Table 1 presents the markers that contributed significantly towards the total variability and variability between GPs.

However, to determine the degree of association between these five GPs, hierarchical clustering was tried using several distance matrix methods, e.g. Jaccard's, Sokal and Sneath5, Anderberg's D, squared Euclidean distance matrix and phi 4-point correlation (www.spss.com). For all of these, the algo- 
TABLE 2. Results of pair wise multiple comparison between profile of GP 1 and others, indicating markers significantly differentiating GP 1 from other four. *, DNA markers; I and J, two groups compared.

\begin{tabular}{|c|c|c|c|c|c|}
\hline Variable* & I & $\mathbf{J}$ & Mean difference & S.E. & P-value \\
\hline \multicolumn{6}{|c|}{ Corrected Model } \\
\hline \multirow[t]{4}{*}{ B810.01 } & 1 & 2 & 1.079 & 0.29 & 0.004 \\
\hline & 1 & 3 & 1.105 & 0.29 & 0.004 \\
\hline & 1 & 4 & 1.053 & 0.29 & 0.005 \\
\hline & 1 & 5 & 0.719 & 0.29 & 0.033 \\
\hline \multirow[t]{2}{*}{ B810.05 } & 1 & 2 & 1.237 & 0.37 & 0.007 \\
\hline & 1 & 5 & 0.825 & 0.37 & 0.050 \\
\hline \multirow[t]{3}{*}{ B810.06 } & 1 & 2 & 0.921 & 0.29 & 0.010 \\
\hline & 1 & 3 & 0.895 & 0.29 & 0.012 \\
\hline & 1 & 4 & 0.947 & 0.29 & 0.009 \\
\hline \multirow[t]{3}{*}{ B810.17 } & 1 & 2 & 1.079 & 0.29 & 0.004 \\
\hline & 1 & 3 & 1.105 & 0.29 & 0.004 \\
\hline & 1 & 5 & 1.053 & 0.29 & 0.005 \\
\hline B811.05 & 1 & 3 & -1.011 & 0.29 & 0.006 \\
\hline \multirow[t]{2}{*}{ B811.08 } & 1 & 2 & 1.079 & 0.44 & 0.034 \\
\hline & 1 & 5 & 1.053 & 0.44 & 0.039 \\
\hline \multirow[t]{2}{*}{ B811.13 } & 1 & 4 & -0.816 & 0.35 & 0.044 \\
\hline & 1 & 5 & -0.816 & 0.35 & 0.044 \\
\hline \multirow[t]{3}{*}{ B812.08 } & 1 & 2 & 1.237 & 0.31 & 0.003 \\
\hline & 1 & 3 & 0.716 & 0.320 & 0.049 \\
\hline & 1 & 5 & 1.158 & 0.317 & 0.004 \\
\hline \multirow[t]{2}{*}{ B855.08 } & 1 & 3 & 1.263 & 0.392 & 0.009 \\
\hline & 1 & 4 & 1.132 & 0.388 & 0.015 \\
\hline \multirow[t]{4}{*}{ B881.04 } & 1 & 2 & -1.237 & 0.369 & 0.007 \\
\hline & 1 & 3 & -1.116 & 0.374 & 0.014 \\
\hline & 1 & 4 & -1.158 & 0.371 & 0.011 \\
\hline & 1 & 5 & -0.825 & 0.371 & 0.050 \\
\hline \multirow[t]{4}{*}{ B881.05 } & 1 & 2 & 1.237 & 0.31 & 0.003 \\
\hline & 1 & 3 & 0.916 & 0.320 & 0.017 \\
\hline & 1 & 4 & 1.158 & 0.32 & 0.004 \\
\hline & 1 & 5 & 1.158 & 0.32 & 0.004 \\
\hline B881.07 & 1 & 4 & 1.053 & 0.47 & 0.050 \\
\hline
\end{tabular}

rithm of average linkage between groups was adopted. It is evident from the results that the four steps of agglomeration are similar for clustering using phi 4-point correlation and distancematrices generated after Euclidean and Sokal and Sneath statistics. However, when clustering was done on the basis of Jaccard's distance matrix, the first two stages were reversed, but resulted in a similar cluster diagram (Fig. 1). In contrast, clustering done using Anderberg's distance matrix produced a completely different picture with the closest distance between GP 1 and GP2. The last agglomeration resulted in a cophenetic correlation of 0.997 compared to the 0.95 for the others. The relationship was further investigated by analyzing individual profiles.

Characterization of five uzi fly groups on the basis of replicated profiles

A total of 83 markers were scored on the ISSR profiles of the DNA from 15 individuals belonging to the four GPs from south India and the DNA ${ }^{\text {mass }}$ of GP 1 . Working with individuals, more markers were scored. For example, using $\mathrm{DNA}^{\text {mass }}$ as the template the primer 810 generated 11 markers, whereas using the same primer with individual DNA, 19 markers generated.

The estimate of Wilk's Lambda from multivariate analysis revealed variability within populations and the variability between GPs was evident from the estimates of Pillai's trace and Roy's largest root. Further, using the multivariate approach, 31 markers revealed significant difference in frequency of occurrence between two groups. Table 2 presents twelve such markers that differed between GP 1 and other GPs. For example, B810.01 revealed significant differences between GP 1 and the remaining four GPs (Table 2), but not between any two of the latter four GPs (data not shown).

Testing for variability between populations using discriminant function analysis

The eighty-three markers, analyzed above, were subjected to DFA. Four functions were identified of which the first two together explain $94.1 \%$ of the variance and had canonical correlation estimates of 0.99 and 0.96 . The $\chi^{2}$ estimate of Wilk's Lambda further supports the significance $(P=0.000$ to 0.022$)$ of these functions. GPs plotted in the matrix of function 1 ( $\mathrm{X}$ axis) against the function 2 (Y axis) are shown in Fig. 2, wherein GP 1, GP 2 and GP 5 appear to have distinct distributions whereas those of GP 3 and GP 4 overlap. The divergence of 30 units on the $\mathrm{X}$ axis between GP 5 from GP 1 is most striking and even that between GP 2 and either GP 1 or GP 5 is also remarkable as they cover $50 \%$ of the $\mathrm{Y}$ axis.

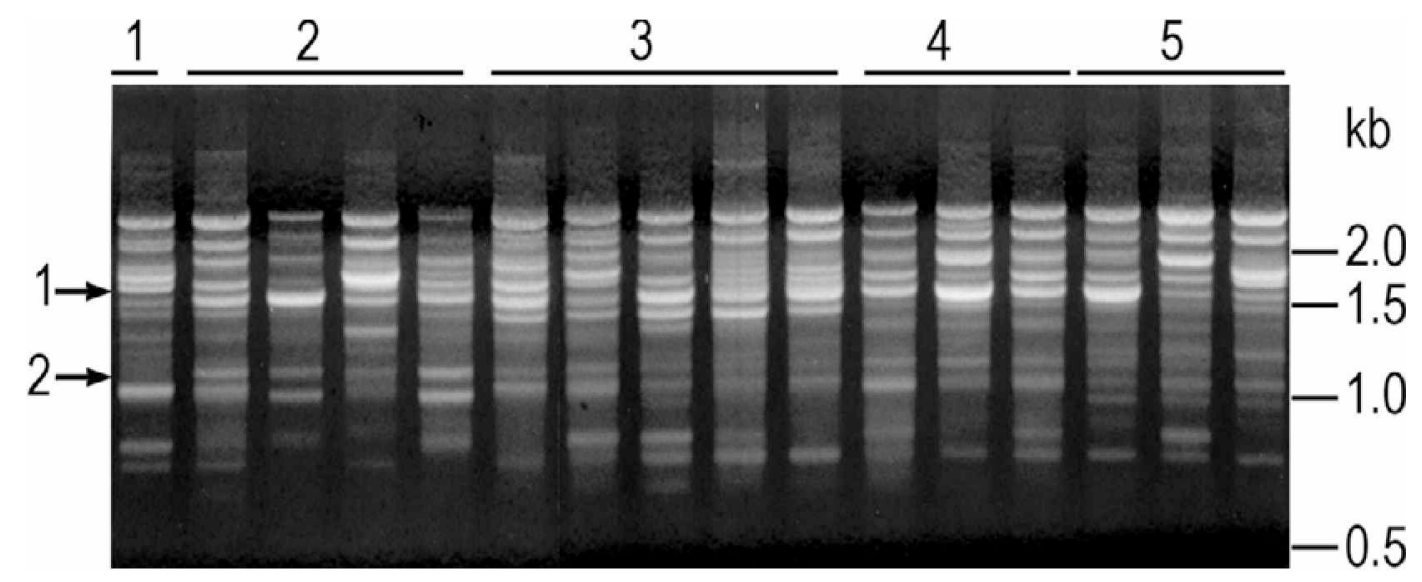

Fig. 3. Sixteen profiles generated with ISSR primer- 881 using the genomic DNA of individuals from four GPs from south India and the DNA ${ }^{\text {mass }}$ of GP 1. Markers 881.07 (arrow, 1) and 881.11 (arrow, 2) were identified by the discriminant function analysis (Table 3). 


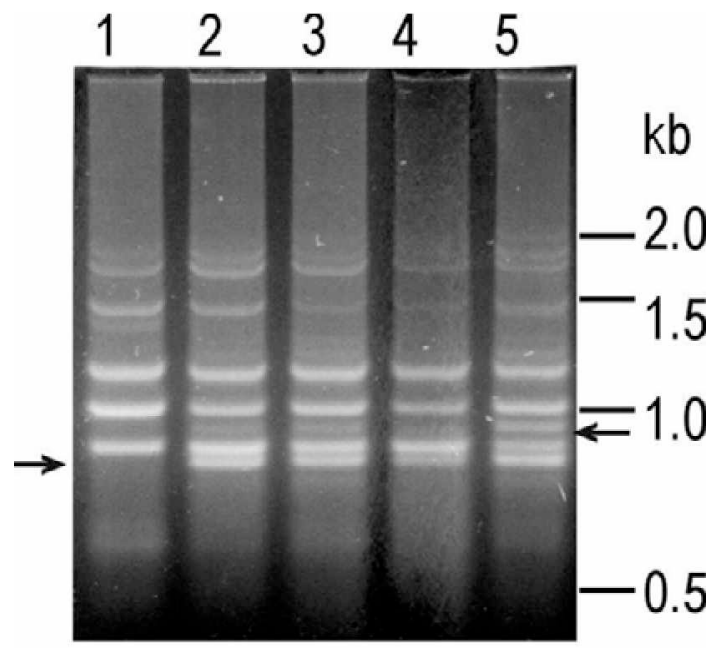

Fig. 4. Profiles of five GPs (lanes 1-5) generated with the ISSR primer-809. Arrows indicate unique absence of markers in GP 1.

This analysis also identified seven (Table 3) out of 83 markers scored in the 16 replicates, which differentially characterize the functions identified, as indicated earlier. Two of the markers are indicated by arrows in Fig. 3. Only four out of the seven primers utilized, generated these seven markers, which varied in size from $0.7 \mathrm{~kb}$ to $3.0 \mathrm{~kb}$.

Data from the ISSR and RAPD profiles were scanned for unique presence or absence of specific DNA markers in a particular GP and the results ae summarized in Table 4. Few of these identified markers are shown in Figs 3-5. There are more such markers in GP 1. Table 4 indicates that the presence and absence of unique markers in the five GPs involved varying number of primers (see Table 4). The number of primers used in the analysis of GP 1 was 8 for unique presence and 6 for unique absence, while for GP 5 it was as few as 1 and 3 for presence and absence, respectively. The absence of RAPD primers (marked with letters OP) is apparent in the profiles for GP 3, 4 and 5 .
TABLE 3. Seven markers identified by discriminant function analysis and the function coefficient of these seven markers for four functions referred to in the text.

\begin{tabular}{lcccc}
\hline $\begin{array}{l}\text { DNA } \\
\text { marker }\end{array}$ & Tolerance & $\begin{array}{c}\text { F-value at } \\
\text { selection } \\
\text { stage }\end{array}$ & $\begin{array}{c}\text { Minimum } \mathrm{D}^{2} \\
\text { (Mahalanobis) }\end{array}$ & $\begin{array}{c}\text { Between } \\
\text { groups }\end{array}$ \\
\hline B810.01 & .024 & 67.447 & 8.487 & 2 and 5 \\
B881.07 & .150 & 13.767 & 13.383 & 3 and 5 \\
B881.11 & .226 & 7.787 & 16.500 & 4 and 5 \\
B855.08 & .088 & 16.951 & 15.583 & 2 and 5 \\
B855.06 & .100 & 11.585 & 15.217 & 2 and 3 \\
B812.08 & .250 & 7.397 & 29.333 & 4 and 5 \\
B812.09 & .191 & 4.809 & 32.633 & 3 and 5 \\
\hline
\end{tabular}

The universal primers also revealed certain differences, but as few markers were scored, these results were not included along with those of ISSR and RAPD. However, the difference between the profile generated for GP 1 and that of the other GPs is illustrated in Fig. 6. Likewise, profiles generated with repeat primers also revealed differences between the profiles of five GPs (Fig. 7). It is also of interest to note that with primer SB534R, a very prominent marker of $\sim 450 \mathrm{bp}$ was identified as a specific marker for GP 1 . The presence and absence of specific markers in the different GPs revealed by using selected primers can be compared with the inference drawn by Wolfe et al. (1998) from their studies on natural population of Penstemon (Scropulariaceae). For example, our results showed that GP 2 and GP 3 are characterized by the presence of six and nine markers generated by five and four primers, respectively, out of the total of sixteen primers used.

\section{DISCUSSION}

The use of ISSR primers revealed $>80 \%$ polymorphism in the population genetic structure, which substantiates their use by others (Fang and Roose, 1997). More than one tool is used to analyze the genetic variability in plant systems (Hess et al., 2000; Davierwala et al., 2000), but rarely animal genomes (Kumar et al., 2001). The present result indicates the usefulness of such an approach.

TABLE 4. List of markers unique for its presence or absence in a particular GP, for the five populations (markers generated using DNA ${ }^{\text {mass }}$ ). "+" and "-" indicate the presence or absence of the marker in that specific GP. The last row is the number of primers used for scoring presence or absence of markers.

\begin{tabular}{|c|c|c|c|c|c|c|c|c|c|}
\hline \multicolumn{10}{|c|}{ List of markers unique for its presence or absence in different localities } \\
\hline \multicolumn{2}{|c|}{ GP 1} & \multicolumn{2}{|c|}{ GP 2} & \multicolumn{2}{|c|}{ GP 3} & \multicolumn{2}{|c|}{ GP 4} & \multicolumn{2}{|c|}{ GP 5} \\
\hline+ & - & + & - & + & - & + & - & + & - \\
\hline 809.06 & 807.02 & 808.01 & 823.08 & 811.07 & 808.04 & 808.05 & 881.08 & 809.05 & 812.01 \\
\hline 810.11 & 807.04 & 808.02 & 835.03 & 823.05 & 808.11 & 810.04 & & & 825.02 \\
\hline 825.09 & 809.11 & 825.05 & 848.05 & 823.07 & 823.10 & 810.05 & & & 825.04 \\
\hline 835.04 & 809.13 & 830.07 & 848.07 & 823.09 & 823.11 & 811.08 & & & 825.08 \\
\hline 835.07 & 823.02 & 835.02 & 848.09 & 848.03 & & 825.03 & & & 830.02 \\
\hline 848.02 & 823.06 & 848.06 & OPH15.07 & 848.04 & & 830.03 & & & 830.04 \\
\hline 855.04 & 855.07 & & & 848.08 & & 881.07 & & & 830.11 \\
\hline 855.09 & OPH13.09 & & & 848.11 & & & & & 830.13 \\
\hline OPH5.08 & OPH13.11 & & & 881.09 & & & & & \\
\hline \multicolumn{10}{|l|}{ OPH13.08 } \\
\hline \multicolumn{10}{|l|}{ OPH13.10 } \\
\hline 8 & 6 & 5 & 4 & 4 & 2 & 6 & 1 & 1 & 3 \\
\hline
\end{tabular}




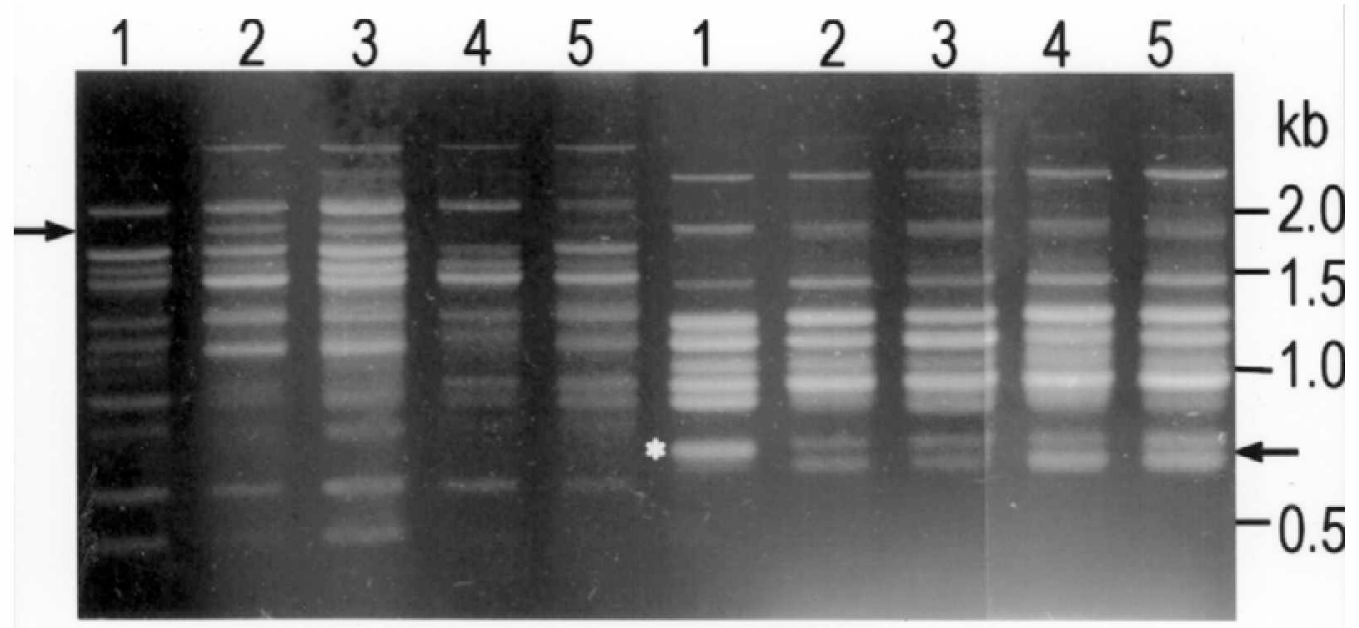

Fig. 5. Profiles of five GPs generated with RAPD primer-OPH-5 (five lanes on left) and OPI-13 (five lanes on right) using DNA $^{\text {mass }}$. Arrows indicate specific markers for GPs 2 and 3 (left) and unique marker for GP 1 (right, *).

\section{Genetic diversity in uzi fly populations from five GPs and its relevance}

The results (Fig. 3) clearly reveal genetic variability between individuals in particular GPs, but what do such differences in profile signify? Assuming microevolution through the accumulation of neutral mutations (Charlesworth \& Wright, 2001), the differences in the ISSR and RAPD profiles may represent small changes in the sequence not leading to any apparent different morpho-physiological or life-history traits. There is a statistically significant association between a group of specific DNA markers and a particular yield trait in Bombyx mori (Sethuraman et al., 2002). It is expected that profiling a large number of individuals of a particular GP would reveal the presence of subgroups within a particular GP, as DNA typing has done for Mycobacterium tuberculosis (Nadler, 1995). The statistical analysis used in this study led to the identification of specific marker(s) in particular GPs, the sequencing of these markers might reveal single nucleotide polymorphism in different individuals from a particular GP, which in turn may throw more

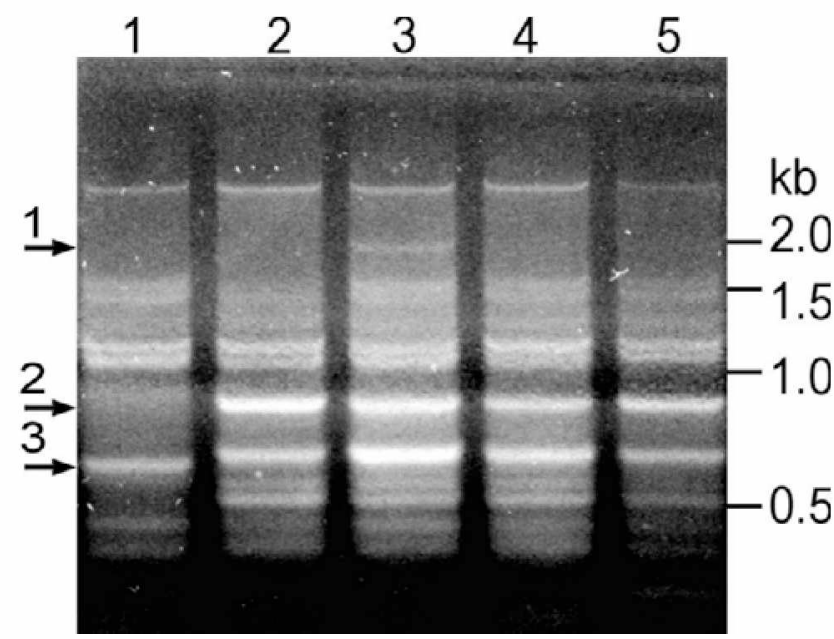

Fig. 6. Profiles of five GPs generated with universal primer-II. The distinct presence of marker 2 2000bp (arrow,1) in GP 3, distinct absence of marker 6900bp (arrow, 2) and presence of $8700 \mathrm{bp}$ (arrow, 3) in GP 1 is evident. light on the rate of microevolution in different populations of $E$. sorbillans.

The statistical analysis confirms that the variation within populations is not significant but that between GPs is significant. The cluster analysis, further reveals the greater divergence of the $E$. sorbillans in GP 1 from those of the other four GPs in the south as is also evident from dendrograms produced using three different statistics (Fig. 1). Anderberg (1973) states that "algorithm can assemble observations into groups which prior misconception and ignorance would otherwise preclude". This is very relevant to the population genetic structure established for the five Exorista populations. However, no comparable data could be found through websites on tachinids. The overlapping distribution (Fig. 2) of GP 3 and GP 4 is expected as they are from two cocoon markets that are only $10 \mathrm{~km}$ apart. But, as farmers come from near and far to these markets the variability is more than that observed in the other GPs

Comparing the result of the DFA which was done with $\mathrm{DNA}^{\text {ind }}$ profiles with the cluster data (derived from $\mathrm{DNA}^{\text {mass }}$ ) indicates that the former has a better resolving capacity. Summarizing, the Exorista samples from the five GPs differ from one another significantly, but the most striking is the difference between GP 1 and the other four. But, what is the relevance of these findings? Does it contradict the earlier report of a single accidental introduction in 1980 of Exorista to the southern states (Samson, 1980), from Murshidabad or Malda?

The distinctness of the GP 1 profile generated using universal primers further strengthens the contention that this population has diverged from those of the southern states. This is because universal primers are more conserved sequences and reveal highly "infrequent difference" between sub populations of a species, and appear to be highly efficient in revealing genetic differences (Buso et al., 2001). The use of the other two primers designed on the basis of repeat sequences of $B$. mori also exposed discrete differences between GP 1 and those from southern states.

The alternative possibility that the uzi fly (Exorista spp.) was present in the south, but silkworm was not its primary host cannot be ruled out, as it is well known to parasitize other Lepidoptera (Clausen, 1940). In that case, it may be presumed that that infusion of the gene pool from West Bengal in 1980s created more genetic variability in the Exorista population in south India and simultaneously there was a fast rate of divergence in the southern states. In this context it is relevant that silkworm is 


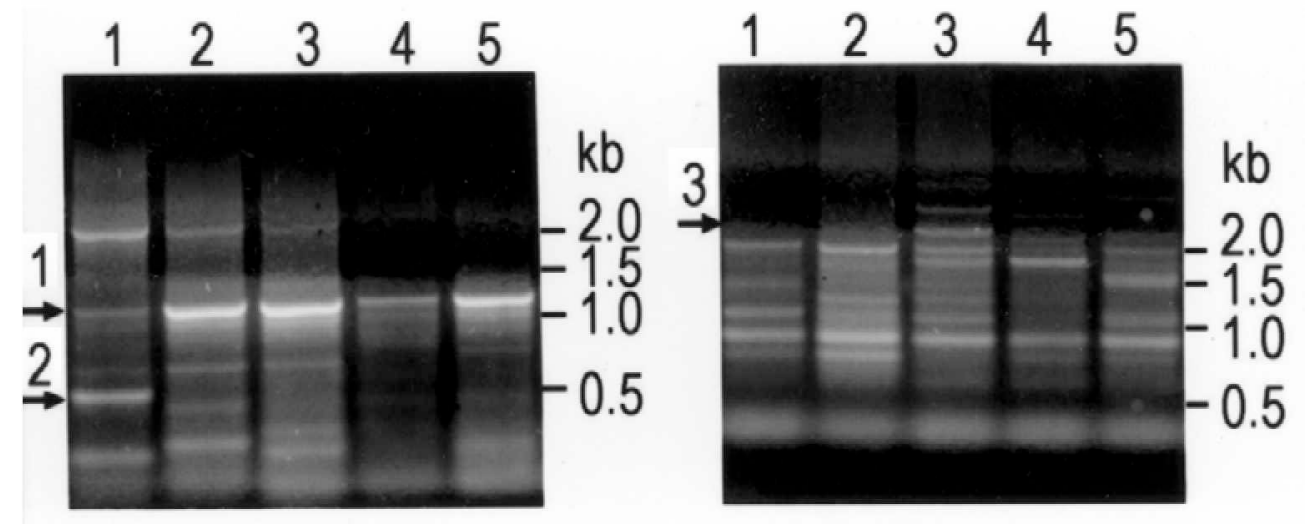

Fig. 7. Profiles generated with primers SBL534R (left) and SBL578R (right) for five GPs of E.sorbillans. The distinct divergence of the other profiles from that of GP 1 is evident. The presence of a specific marker, of $\sim 450 \mathrm{bp}$. is marked with arrow 2 . The other two (arrows 1 and 3) indicate allelic difference in the five GPs.

grown continuously in south India and provides a host on which this pest can complete several generation per year. This would facilitate a faster rate of divergence. All these aspects expand the scope of a further in depth study on E. sorbillans.

ACKNOWLEDGEMENTS. S.N. Chatterjee, earnestly expresses his gratitude to Arun Ramanathan, IAS for bringing him to the institute and to P. Joy Oommen, IAS (CEO) for his continuous support. Further, we wish to thank Beera Saratchandra, and Pranab Mukherjee, Director and Joint Director, Central Sericulture Research \& Training Institute, Berhampore, West Bengal for providing uzi fly maggots from the stock maintained at that institute. The study was carried out with grants-in-aid from Central Silk Board, Ministry of Textiles, Government of India.

\section{REFERENCES}

Anderberg M.R. 1973: Cluster Analysis for Applications. Academic Press, New York.

Buso G.S.C., Rangel P.H.N. \& Ferreira M.E. 2001: Analysis of random and specific sequences of nuclear and cytoplasmic DNA in diploid and tetraploid American wild rice species (Oryza spp.). Genome 44: 476-494.

Clausen C.P. 1940: Entomophagous Insects. Mac Graw-Hill, Book Company, Inc. New York \& London, $688 \mathrm{pp}$.

Charlesworth D. \& Wright S. 2001: Breeding system and genome evolution. Curr. Opinion Gen. Dev. 11: 685-690.

COTES E.C. 1889: Further notes on insect pests-14. Short notes on miscellaneous insect pests - Diptera. Indian Mus. Notes 1: $63-64$.

Davierwala A.P., Chowdari K.V., Kumar S., Reddy A.P., RanJEKAR P.K. \& GUPTA V.S. 2000: Use of three different marker systems to estimate genetic diversity of Indian elite rice varieties. Genetica 108: 269-284.

FANG D.Q. \& Roose M.L. 1997: Identification of closely related citrus cultivars with inter-simple sequence repeat markers. Theor. Appl. Genet. 95: 408-417.

Grosh C.C. 1949: Silk Production and Weaving in India. Monograph, Centre of Scientific and Industrial Research, Govt. of India, pp. 52-62.
Hess J., Kadereit J.W. \& Vargas P. 2000: The colonisation history of Olea europa L. in Macaronesia based on internal transcribed spacer 1 (ITS-1) sequences, random amplified polymorphic DNAs (RAPD), and intersimple sequence repeats (ISSR). Mol. Ecol. 9: 857-868.

Kumar L.S., Savant A.S., Gupta V.S., \& Ranjekar P.K. 2001: Comparative analysis of genetic diversity among Indian populations of Scirpophaga incertulas by ISSR-PCR and RAPD-PCR. Biochem. Genet. 39: 297-309.

MukHerjee N.G. 1899: Hand Book of Sericuture. Govt. Book Depot, Calcutta, India.

NADLER S.A. 1995: Microevolution and the genetic structure of parasite populations. J. Parasitol. 81: 395-403.

Narayanaswamy K.C. \& Devaiah M.C. 1998: Silkworm Uzifly. Zen Publishers, Bangalore, India, pp. 1-6.

Narayanaswamy K.C., Kumar P., Manjunath D. \& Datta R.K. 1994: Determination of flight range of uzifly, Exorista bombycis (Louis) (Diptera: Tachinidae) through marking technique by adding dye to adult diet. Indian J. Seric. 33: $40-43$.

SAMSON M.V. 1980: War on uzifly. Indian Silk 9: 21-23.

Sengupta K., Kumar P., Baig M. \& Govindaiah M. 1990: Handbook on Pest and Disease Control of Mulberry and Silkworm. United Nations Economic and Social Commission for Asia and the Pacific, Bangkok, Thailand.

Sethuraman B.N., Mohandas T.P. \& Chatterjee S.N. 2002: DNA fingerprinting with homologous multilocus probes and search for DNA markers associated with yield attributes in silkworm, Bombyx mori. Eur. J. Entomol. 99: 267-276.

VANDER Wulp F.M. 1896: Parasitic Muscidae from British India-3, Tricholyga bombycis Beck. Indian Mus. Notes 3: $8-15,41-42$

Wolfe A.D., Xiang Q.Y. \& KepHart S.R. 1998: Assessing hybridization in natural populations of Penstemon (Scrophulariaceae) using hyper variable inter simple sequence repeat (ISSR) markers. Mol. Ecol. 7: 1107-1125.

Received June 11, 2002; revised November 28, 2002; accepted January 6, 2003 